\title{
The Facebook Groups and Pages of Malagasy Migrants in France: Hubs of Peer-to-Peer and Spontaneous Solidarity
}

\author{
Fortunat Miarintsoa Andrianimanana * and Carles Roca-Cuberes \\ Critical Communication Group, Pompeu Fabra University, 08018 Barcelona, Spain; carles.roca@upf.edu \\ * Correspondence: fortunatmiarintsoa.andrianimanana01@estudiant.upf.edu
}

Citation: Andrianimanana, Fortunat Miarintsoa, and Carles Roca-Cuberes. 2021. The Facebook Groups and Pages of Malagasy Migrants in France: Hubs of Peer-to-Peer and Spontaneous Solidarity. Social Sciences 10: 420. https://doi.org/10.3390/ socsci10110420

Academic Editor: Nigel Parton

Received: 8 August 2021

Accepted: 31 October 2021

Published: 4 November 2021

Publisher's Note: MDPI stays neutral with regard to jurisdictional claims in published maps and institutional affiliations.

Copyright: (c) 2021 by the authors. Licensee MDPI, Basel, Switzerland. This article is an open access article distributed under the terms and conditions of the Creative Commons Attribution (CC BY) license (https:// creativecommons.org/licenses/by/ $4.0 /)$.

\begin{abstract}
How do social platforms such as Facebook help migrant communities cope with the adversities faced during the migration journey? This is the question that drove this study, which explores the on- and offline experiences of Malagasy migrants in France during their migration journeys. We use complementary mixed methods, including an online survey $(2021, \mathrm{n}=340)$ and participant observation of in-group and public interactions on 28 Facebook groups and pages of this community. We found that peer-to-peer solidarity as a collective response to the adversities faced during migration is present and very active within the Malagasy community in France. The exchanges among the members of this community concerning matters such as administrative issues and the transport of parcels between France and Madagascar are intense and continuous. Beyond this, solidarity chains are temporarily activated in response to specific needs, and particularly in collectively challenging times such as the COVID-19 pandemic. Our research also found that in their groups and pages, the Malagasy in France engage less frequently in other vital issues, such as finding work.
\end{abstract}

Keywords: Malagasy diaspora; e-diaspora; transnational solidarity; Facebook; imagined community

\section{Introduction}

The unprecedented COVID-19 pandemic has led us to revisit the issues of human (im)mobility and online togetherness, and the question of communities. It has also reminded us of the vital role played by digital platforms such as Facebook in nurturing and maintaining communities and in collectively dealing with shared adversity. This paper considers one of the migrant communities hit hard by the pandemic: Malagasy migrants in France. Most Malagasy migrants found themselves trapped by the separation from their loved ones, and sometimes by the loss of family members, due to the closed borders of their country of origin for more than a year and a half. At the same time, they were affected by the restrictive measures taken against the COVID-19 pandemic within their host country. As a consequence, their sense of belonging to a community had never been challenged to such a degree. In this paper, we examine the self-organised structures the Malagasy migrants in France used to face this challenge.

\subsection{Imagined (Migrant) Communities, COVID-19, and Facebook}

The physical distancing and social isolation measures taken around most of the world to fight against the COVID-19 outbreak brought together communities of all kinds online (Wiederhold 2020). For obvious reasons, socially determined circles such as families, lifelong friends, and colleagues are likely to have set meeting routines (Lebow 2020), for these circles are composed of people who know each other and who maintain a determined type of relationship. For less obvious reasons, people coming from different geographical locations, ages, genders, and other variables found themselves gathering on online platforms during the successive lockdowns. In these spaces they created online and 'imagined communities' whose members had no previously determined relationship. They rarely 
gathered for collective entertainment, worship, debates, or conferences, to name but a few motives. In contrast to the first kind of circles, these 'imagined communities' were formed by people sharing the same values, aspirations, tastes, ambitions, political standpoints, cultures, countries, etc. (Kriz 2020; Parish 2020; King et al. 2020; Amin et al. 2020). For these 'imagined communities', having something in common appears to be the key factor in the creation and maintenance of such circles. Although 'imagined communities' have always existed-before online platforms they were created in bars, children's playspaces, gaming rooms, etc.--today's 'imagined communities' are different because of how they deal with the issues of connectivity and ubiquity.

'Connectivity' drives human relationships, circles, and communities. The aforementioned bars, children's playspaces, gaming rooms, etc., paved the way for other kinds of meeting spaces such as online forums, videoconferencing platforms, as well as instant and group messaging platforms. Humans are embracing the 'era of connectivity' as well as the era of online social networking platforms (Diminescu 2008). People with shared common factors and desire to belong to a community can instantly find one, as being part of a community has never been so easy, as long as they remain connected through digital technologies.

'Ubiquity' best describes the current post-mobility era (Twigt 2018; Wilson et al. 2012). Through continuous and intense connectivity, humans are physically in one place yet present everywhere. Geographical boundaries have never been blurrier when it comes to (imagined) community building. Physical distance is increasingly being challenged by video conferences, voice calls, group chats, online forums, and other digital meeting points and spaces enabled by digital technologies. Social networks bring together people who feel that they belong to a community.

'Imagined communities' are composed of a mixture of people who share a common cultural identity and aspirations enabled through connection as well as ubiquity (Anderson 1983; Georgiou 2019; Tsagarousianou 2004). However, what makes these connected or online imagined communities different from physical and legally constituted communities is that membership in their communities goes beyond traditional access or duties.

(Online) migrant communities such as those of Malagasy migrants in France-the subjects of this paper-fit perfectly into this understanding of imagined communities. Where the communities that form around a celebrity gather around the same icon or idol, migrant communities unite around a shared culture or country. The most interesting dynamic in migrant communities is the interconnection of their members despite their obvious heterogeneity, which appears to be enabled by a shared country of origin. Amongst migrant communities, there is (i) constant connectivity both within their host countries and with their country of origin, and (ii) ubiquity, since they are physically in their host countries and at the same time very present in their countries of origin (Diminescu 2008, 2012). Some scholarly studies have shown that migrant communities have organised themselves online and offline for different purposes. Most of them have shown that the gathering of migrant communities goes beyond simple 'togetherness' and can lead to a wider spectrum of common actions (Ajder 2020; Marino 2015; Kumar 2012; Mesbah and Cooper 2019; Nancheva 2021; Aboussi 2020). In comparison to other imagined communities, the community building of migrant communities is even more complex since it is intimately intertwined with the feeling of national belonging, which is the result of a mixture of national pride and belief in a shared culture and origin (Christensen 2012; Christiansen 2004; Ellison 2013; Elling et al. 2014).

This paper elucidates the experience of a very understudied community, Malagasy migrants in France, in terms of the theoretical concept of 'imagined communities'. It seeks to explore whether this community, whose members are heterogeneous, relies on self-organised structures on social networking platforms. Additionally, it seeks to explore the self-organised communitarian actions within the community as they cope with common adversities faced during their migration journeys, particularly during the COVID-19 pandemic. 


\subsection{An Overview of Malagasy Migrant Communities in France}

With approximately 150,000 individuals, France is the first destination of Malagasy migrants. Nine of every ten Malagasy migrants live in Europe and $85 \%$ of them are residents of France, including both metropolitan and overseas territories. This makes Malagasy migrants the largest sub-Saharan migrant community in France, after migrants from Algeria, Morocco, and Tunisia (Kotlok 2016; Razafindrakoto et al. 2017).

The life of Malagasy migrants in France features a wide range of adversities that encompass every stage of their migration journey. These adversities begin in their homeland, where transnational migration appears to be mainly motivated by social adversities such as chronic economic poverty and cyclical political turmoil. The increase in the number of Malagasy migrants in France from 76,000 in 2000 to 148,000 in 2005 (Razafindrakoto et al. 2017, p. 10), for example, attests that their migration is intimately related to the political turmoil of 2002. After what is often a traumatic escape from their country of origin, most Malagasy migrants in France face the challenge of settling into a new society. Although 'culture shock' and integration are common phenomena faced by almost all immigrants, the immense structural economic differences between their country of origin and their country of settlement is another significant challenge faced by the Malagasy in France.

Yet, existing studies on Malagasy migrants in France show that the specific adversities they face go well beyond these cultural and economic gaps, for they must also contend with the phenomenon of 'social downgrading'. This term refers to the downward shift of migrants' social status in the host country. As 'potential elites' in Madagascar-highly educated people from the Malagasy bourgeoisie (Claverie 2011; Claverie and CombeauMari 2011; Crenn 1994; Kotlok 2016; Razafindrakoto et al. 2017)—they see the boundaries of their social status become blurrier as they are downgraded to 'ordinary people' once settled in France. This is not only a social but also psychological challenge for them.

As for community building, Malagasy migrants in France rely on offline and powerful self-structured associations that gather the members of the communities for mostly festive or religious motives (Claverie 2011; Crenn 1994; Rabeherifara 2009). Studies find the Malagasy in France to be very active within associations related to Malagasy churches settled in France. They also have an annual appointment, the Rencontre National Sportif (RNS), which includes sports contests organised by and for Malagasy migrant communities (Claverie 2011). These social structures were created to help the Malagasy in France 'feel the Malagasy rhythm while being in France', as a slogan of an annual venue of RNS puts it.

Recent studies have shown that Malagasy migrants in France use online platforms as tools for community building and for displaying their shared and common identity (Andrianimanana and Roca-Cuberes 2019; Rakotoary 2019). In line with these studies, this paper focuses on the online social dynamics of these Malagasy migrants, who have mostly been studied through analyses of their offline activities in the existing literature.

\section{Research Design}

To answer the research questions, this paper relies on complementary mixed methods that include Netnography (applied to Facebook) and an online survey. Netnography was used to search for the online self-organised structures of Malagasy migrants and, when they existed, to explore the self-organised actions undertaken as a community within them to cope with the adversities faced during their migration experience. The online survey was designed to complement the Netnography and was designed to explore the personal intentions of Malagasy migrants for engaging in the construction of communities both online and offline.

The Netnography analysis (Kozinets 2002; Bowler 2010) was conducted on twentyeight groups (both private and public) and pages from March 2020 to July 2021. It relied on the following four interdependent and complementary steps.

Step 1: Identification of groups and pages on Facebook. Apart from those groups and pages known by the authors before this research, the groups and pages on Facebook were searched for manually using keywords such as "Malagasy eto Frantsa", "Gasy eto 
Frantsa" or "Malgaches en France" (meaning "Malagasy in France" in the Malagasy and French languages). In total, forty-two groups and pages were found in this first step. All forty-two groups, whether private or public, were selected for initial consideration. While public groups (four out of the total) were easily accessible, access to private groups was moderated by their administrators and we answered some questions (most of the time in Malagasy) and/or gave them some personal data before being accepted (or not) into the groups. Our requests for access to four groups were denied.

Step 2: Selection of the groups to be analysed. In order to analyse spontaneous, unofficial, and day-to-day conversations between ordinary Malagasy citizens, conversations were retained from the forty-two groups found in the previous step, i.e., large, active groups and pages run and/or managed by and for ordinary Malagasy citizens in France with more than one hundred followers or members. The following were excluded: groups and pages run and/or managed by and for Malagasy migrants in France that represent or are related to Madagascar's foreign representations abroad (such as its embassy or consulates), those run and/or managed by non-Malagasy citizens, and those that denied our membership requests. In total, twenty-eight of the forty-two groups and pages identified in Step 1 were retained for the analysis. The geographical location of the administrators of the groups and pages, i.e., France, were publicly visible on Facebook as part of its commitment to transparency. The citizenship of the administrators was easily detected by their (nick)name(s) and, on some occasions, by the questions asked in applications for membership to the groups or by the rules set within the group-usually in Malagasy. Additionally, the citizenship of the administrators was easily detectable since they moderated conversations in almost all the groups by providing some comments in Malagasy.

Step 3: Detection and selection of the conversations and interactions to be analysed. Posts and conversations that took place between March 2020 and July 2021 were retained. This timeframe was selected in order to comprise conversations and interactions that took place throughout the core of the COVID-19 pandemic. Conversations and interactions occurring in uncertain and socially (as well as individually) challenging times such as the COVID-19 pandemic were deemed particularly relevant to shedding light on our research questions dealing with social and individual online solidarity mechanisms put in place by Malagasy migrants. Therefore, conversations were analysed weekly and directly noted.

Step 4: Analysis of the conversations and interactions. Above all, for ethical and privacy reasons, conversations and interactions were not downloaded from the platform, nor was the personal information of the members who interacted in the conversations downloaded. The conversations were analysed weekly and the results were directly made note of, with a focus on the frequency, intensity, topics, and engagement rates (number of reactions, shares, and comments) of the interactions.

We chose Facebook for our analysis as it is by far the most used social networking platform in the world, with more than 2.7 billion users in 2020 - the equivalent of more than $65 \%$ of total active social network users (DataReportal 2020, p. 93). In this sense, for Malagasy migrants in France, we understand Facebook to be "inevitably mainstream and more demographically representative" (Kozinets 2010, p. 10). We also chose Facebook for methodological reasons, since Facebook is an online space for communities, where the observation of social dynamics is "faster, simpler, cheaper, naturalistic, and unobtrusive" (Kozinets 2002, p. 1) compared to offline observations. Finally, this choice was motivated by the proven relevance of this platform, since other empirical studies of other diaspora communities in the same line have already been successfully carried out on Facebook (Nancheva 2021; Mesbah and Cooper 2019).

The online survey was conducted from 23 to 28 March 2021 with the Google Forms platform, which is commonly used for online surveys due to its ease of use. The online survey was relayed to members through the Facebook groups of Malagasy migrants by the authors before the Netnography was conducted in order to reach more informants $(n=340)$. Apart from basic demographic variables (such as age, gender, region and length of residence in France, level of education, and professional status), the questionnaire also collected 
information on variables relating to the affiliation of the informants to Facebook group(s) and page(s) created and/or managed by and for Malagasy migrants. The online survey also included questions on the affiliation of the informants with any offline organisation or groups created and/or managed by and for Malagasy migrants in France.

\section{Results}

\subsection{Active and Popular Self-Created Facebook Groups and Pages}

Facebook groups and pages are highly popular among Malagasy migrants in France. As mentioned in the previous section, there are at least forty-two groups and pages whose numbers of members and followers range from 110 to 151,000 in total. The Facebook groups and pages of Malagasy migrants in France are used as gathering spaces for various motives. Some were created to bring together Malagasy migrants from a given geographic area for no specific reason. This is the case for the groups Malagasy à Paris ("Malagasy in Paris", 2721 members, created in 2016), Gasy de Toulouse ("Malagasy in Toulouse", 2400 members, created in 2012), Malagasy à La Réunion ("Malagasy in La Reunion Island", 2722 members, created in 2016), Groupe de Diaspora-Malagasy de Poitiers ("Group of the Malagasy diaspora in Poitiers", 274 members, created in 2020), and the most popular Malagasy page of the Malagasy in France named Malagasy en France ("Malagasy in France", 151,236 followers, created in 2013).

Other groups and pages were created for mutual aid and solidarity between the members of the Malagasy migrant communities. This is the case for groups such as Malagasy Mifanampy eto Frantsa ("Malagasy Helping Each Other in France", 1623 members, created in 2018) and Gasy Miray hina sy mifanoro hevitra eto Frantsa sy Europe ("United Malagasy in France and Europe", 2809 members, created in 2018). These groups are used as community spaces for Malagasy migrants in France who need or offer a wide range of help. For example, Réseau malgache d'entraide pour nourrir les démunis durant le confinement ("Madagascan mutual aid network to feed the needy during lockdown", 4100 members) was created spontaneously in 2020 at the start of the Coronavirus pandemic in response to a spontaneous and temporary need. Its sole objective is to bring together Malagasy migrants to help the poorest families in Madagascar in specific circumstances. In the same line of solidarity, the Gasy Misera Nationalité eto France (Conseils et Rex Nationalité Française) group ("Malagasy group of information and guidelines on French citizenship", 6200 members, created in 2018) was created specifically to provide mutual assistance with administrative procedures in France, including applications for French citizenship.

Pages such as Discothèque malgache Paris France ("Malagasy discos in Paris, France", 7531 members, created in 2011) and Fêtes malgaches de Toulouse ("Malagasy parties in Toulouse", 1923 members, created in 2012) were created for leisure and in particular festive events. Groups such as Rencontres Malgaches en France et Europe ("Malagasy dating in France and Europe", 789 members, created in 2016) or Gay malgache en France ("Malagasy gays in France", 289 members, created in 2013) are used as online dating spaces for Malagasy migrants.

Some were created for commercial exchange of goods and services between Malagasy migrants in France. Groups such as Gasy Serasera eto Frantsa-GSF Ofisialy ("Official Malagasy Communication group in France", 14,100 members, created in 2013), Gasy Sera eto Lyon ("Malagasy Communication group in Lyon", 1000 members, created in 2016), Vide Dressing des Mamans Gasy de France ("Clothes-swap group of Malagasy mummies in France", 646 members, created in 2018) and Le boncoin Gasy du Sud de France ("Malagasy Le boncoin in Southern France, 2700 members, created in 2018) are examples of such groups. The public description of the latter sums up the motives of this category of groups: "We created this group to bring together the Malagasy community in the South [of France] and to allow everyone to have their little business of Malagasy products or others here in France".

We also found Malagasy church groups such as FPMA Evry Fitiavana ("FMPA Evry Love", 110 members, created in 2014). According to the public description of the group, it is 
intended "to communicate, to share messages, information ... and everything concerning the life of the church [FMPA of Evry]". The same description mentions that this group "respects the rules and values of the FPMA". The acronym "FPMA" seemed curious to us because of its meaning: Fiangonana Protestanta Malagasy aty Andafy ("Malagasy Protestant Church in France"). The FPMA group is a subsidiary of the national structure of the FJKM church (Fiangonan'i Jesoa Kristy eto Madagasikara) ("Church of Jesus Christ in Madagascar"), which is a Protestant reformed church and one of the most-frequented churches in Madagascar.

Finally, other groups were created for social claims directed at Madagascar's institutions. For example, the group 'Za koa hifidy-later renamed 'Za koa hanorina ("I want to build too", 14,100 members, created in 2018 on the eve of the Malagasy presidential elections of the same year) — called for the organisation of a symbolic consultation of the voting intentions of Malagasy migrants in France. The purpose of the group Nous sommes aussi des malgaches - donnez-nous le droit de voter ("We are also Malagasy-give us the right to vote!", 1725 members, created in 2013) is also in line with the previous group.

This brief overview of groups and pages shows the existence of structures and organisations built by and for Malagasy migrants in France on Facebook. We discovered that while these groups and pages are self-constructed, they are also self-regulated and self-moderated by ordinary Malagasy citizens. The constitution of these groups and pages is similar to that of communities governed by shared cultural codes on the one hand and by civility and civic morals on the other. The use of Malagasy proverbs such as "tsy misy manana ny ampy fa sambatra izay mifanampy" ("No one is self-sufficient, blessed are those who help each other") as the governing law for some groups attests to the importance of the cultural component in the construction of these groups, as is the case of the GSF group in Figure 1. Despite the fact that these groups and pages have been structured around very specific purposes, in general, they are made to bring Malagasy migrants together in France and to facilitate their migratory experience. The names and purposes of the groups show the main adversities faced by the Malagasy migrants in France in a comprehensive way. These adversities can be linked to administrative difficulties within their host country, the limitation of their rights vis-à-vis their countries of origin, not to mention day-to-day material difficulties, etc. The following section addresses in detail the in-group interactions addressing these adversities and the personal and collective solidarity actions undertaken by the Malagasy migrants to deal with them.
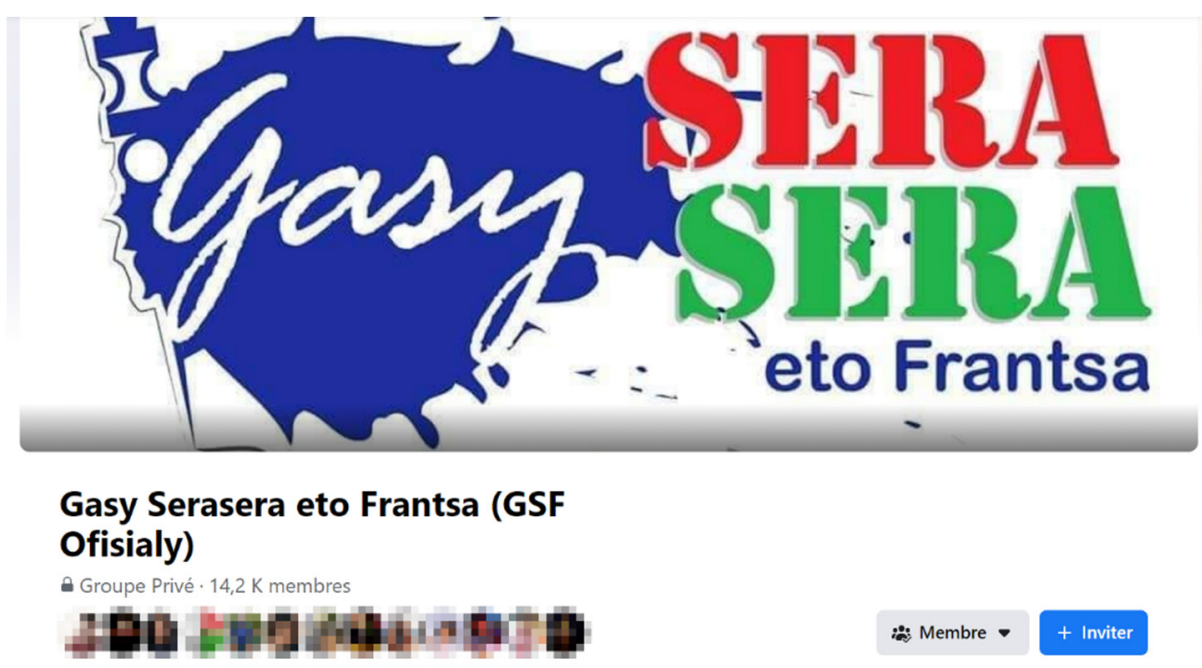

Figure 1. Capture of the largest Facebook group of the Malagasy in France: Gasy Serasera eto Frantsa (GSF)-14,200 members. 


\subsection{Facebook Groups and Pages: Hubs for Peer-to-Peer Solidarities}

The posts within each group vary because they do not all have the same purpose. Within the largest groups, the most popular and frequent posts are related to offers and requests for parcel shipping on flights between France and Madagascar. Within groups, these posts are displayed first by the Facebook algorithm because of their almost daily frequency and their popularity in terms of engagement rates. Usually written in a contracted Malagasy language, comments on these posts feature expressions of courtesy such as "azafady" (please) or "tompoko" (Madam/Sir), which encourage cordial exchanges. The interested users are generally invited by the post's author to continue the exchanges through private messages for more details and final formalities.

For example, in July 2020, a young man in his thirties offered his services to a group: “Bonjour groupe. Poids Tanà-Paris $23 \mathrm{~kg} \times 2$ dispo le 17 juillet. $12 € \mathrm{le} \mathrm{kg}$, $10 €$ pour les enveloppes. Pas de cigarettes, d'alcool ou d'objets sujets à des complications aux douanes. À rendre à xxx et à récupérer à xxx. Merci." ("Hello group. Tanà-Paris $23 \mathrm{~kg} \times 2$ available on July 17th. $€ 12$ per kg, $€ 10$ for envelopes. No cigarettes, alcohol, or items subject to customs complications. Pick up in xxx [a square in Antananarivo] and delivery in xxx [a city in France]. Thank you") (see Figure 2).

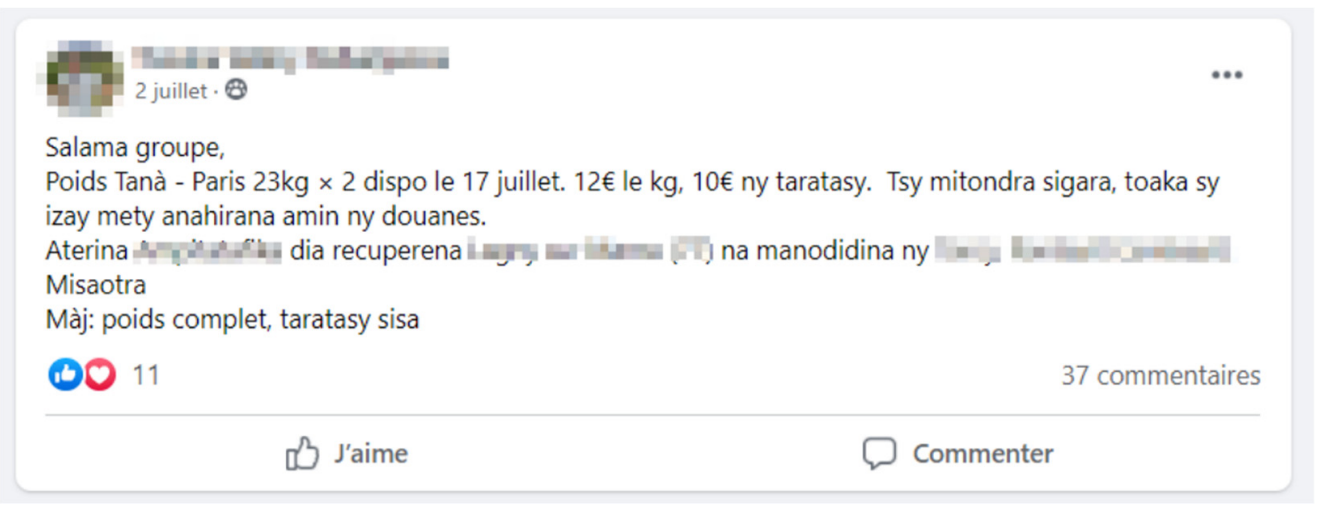

Figure 2. Capture of an offer of freight from the GSF group.

The brevity of the information provided by the author and the popularity of the post show the familiarity of the members of the group with this type of post. The thirty remarkably courteous interactions on this post appeared for three days until the offered 'weight' was exhausted. These interactions were short, and the author of the post invited each commentator and potential 'buyer' to private message to close each conversation. The post was closed by its author about ten days before his departure.

Posts related to administration and bureaucracy are also popular within the groups we observed. While they appear as sporadic but frequent posts in generalist groups, there are also entire groups dedicated to resolving such issues. Discussions on visa and residence permit applications, passport renewal procedures, and procedures for applying for French naturalisation are the most recurring topics. A Malagasy father, residing in France and traveling to Madagascar, wrote in one group: "Bonjour GSF. De passage à Madagascar et titre de séjour égaré, j'ai demandé un visa de retour. Quelqu'un serait-il passé par là ? Combien de temps cela leur prenait-il ?" ("Hello GSF [the name of the group]. While in Madagascar, I lost my residence permit, I applied for a return visa [in the French Embassy in Madagascar]. Has anyone gone through this? How long did it take them?") (July 2020). Most of the interactions with this post were emotional support and encouragement (for example, "Good luck, we've been there!") from other members of the group. Some other members of the group offered advice on how to avoid such incidents and to secure French documents when travelling to Madagascar. A number of other comments based on personal experiences were offered as answers to the post. One participant in the discussion posted a link to the official website of the French government, mentioning the procedures to be undertaken in the specific case of loss of a French residence permit while abroad. 
The same interaction scenario was quite frequent within the group dedicated to applications for French citizenship. Offers of support and assistance based on personal experience and/or knowledge of the members of the group are very commonly repeated within this group in response to others' personal cases and problems related to these applications. These range from a simple question on the procedures for the application for naturalisation to others requiring careful attention to detail, such as the inscription of a newborn in the birth registry by a new French husband and the request for naturalisation of the child. Other cases had to do with the recognition of the French citizenship of deceased grandparents so that their grandchildren could obtain French citizenship, or the recognition of a child born out of wedlock by his French father. These peer-to-peer interactions on bureaucratic questions, which featured government websites and are displayed in the description of the group, helped us to understand the nature and importance of such informal support groups.

Professional service offers and demands are also among the most recurrent posts. Some posts sought recommendations for drivers, nannies, dentists, painters, masons, lawyers, etc., within the groups. Nonetheless, what makes the interactions on professional exchanges curious is, apart from the fact that there is no dedicated group to this issue, the existing posts on this topic are frequent and at the same time unpopular (receiving barely one or two reactions) in the generalist groups where they are posted. Moreover, the authors of the posts are sometimes cautious. It is common to find service requests that mention "mpiasa tsy tara lava na 3 andro vao vita" ("workers who will not arrive late and take 3 days to complete the job"). The lack of visibility of France-based Malagasy entrepreneurs and the little interaction with these posts were striking and led us to speculate that: (i) the exchanges on this matter go directly to private messages, or (ii) due to the COVID-19 pandemic, outdoor works were very much reduced, or (iii) the Malagasy migrants make little exchanges on professional services, or (iv) there are other communication channels where discussions on professional service exchanges take place.

The sudden COVID-19 pandemic sparked practical and emotional support chains among the Malagasy within the studied groups. Help-seeking posts abounded and attracted many reactions in a remarkably short period. For instance, faced with the sudden death of their respective mothers in Madagascar, two women in their thirties and forties posted in two different groups and each received approximately 120 comments in less than twenty-four hours in September 2020. Although the posts focused on bureaucratic matters such as "Quelles sont les démarches pour l'obtention de l'autorisation?" ("What are the procedures for obtaining an authorisation [to enter Madagascan territory]?") or "Où pouvons-nous effectuer les tests PCR pour rentrer à Madagascar" ("Where can we get PCR tests to return to Madagascar?"), the comments were mainly expressions of condolences written in Malagasy. A few top-rated comments publicly offered advice on what to do based on their personal experiences or invited the author to private communications for the same purposes.

Spontaneous solidarity initiatives in response to the COVID-19 pandemic were organised by members of the Malagasy community in France and were shared within different groups. In March 2020, the image of "Bebe Antsika" ("our grandmother") - a 65-year-old Madagascar-based woman who kept her magazine kiosk open during the imposed lockdown for economic reasons-went viral among the groups of the Malagasy migrants in France. An online crowdfunding was organised by a group of Malagasy in France and reached 1292 euros in a few days. This story was so popular that a Facebook page dedicated to the woman was created which showed how she was using the fund in Madagascar. In the same line, a post of a lady asking for help in November 2020 quickly became very popular, with 400 reactions and 150 comments in a single day. In the post, the author narrated her encounter with a Malagasy student sleeping on the streets of Paris after losing his job. Maintaining the student's anonymity, the post's author asked for material support that she could forward to the student. Although the post was very popular, the opinions of the commentators were divided on the question. While some appealed for "samy malagasy" 
("between Malagasy") generosity, others warned donors about donations to anonymous people and shared their negative experiences with this type of support.

This sort of spontaneous chain of solidarity was also observed within groups around the Christmas season. The manager of the GSF group organised annual public "Noël Solidaire" prize pools for Malagasy students in France whose families were in Madagascar. The organisation of this type of crowdfunding within the group is quite interesting. They are presented within the groups as professional advertisements with well-crafted infographics. Even though the posts generated little visible interactivity (with barely nine reactions and no comments), they were very much effective. The group's administrators launched the pool in the group and at the same time opened online registration for needy students who wished to be recipients of the funds; once the total amount was collected (in 2020, 4172 euros), it was equitably distributed to the previously registered students. In parallel, other group members invited the students to spend Christmas day with their families, indicating the number of students they could accommodate.

The Malagasy in France use their groups and pages as spaces for collectively sharing and celebrating Malagasy success stories worldwide. The popularity of several series of posts on Margherita Davico ("Marghe"), a young singer of French-Malagasy origin who won the song contest "The Voice" in France in 2020 attests this. Some days before the final contest, a post about Marghe in the 'Za Koa Hanorina group proclaimed "Alefa Madagascar. Marghe est en finale" ("Go Madagascar! Marghe is in the final [of the The Voice competition]") in the group from a public page. A few days later, photos of Marghe's victory were posted in the group with two very popular posts (863 reactions and 114 comments) and with captions featuring Madagascar flag emojis as well as words such as "national pride". Beyond the feeling of national pride manifested in the reactions and in the comments, practical and material solidarity was shown through the massive participation of Malagasy people in France during the public vote for the competition (see Figure 3).

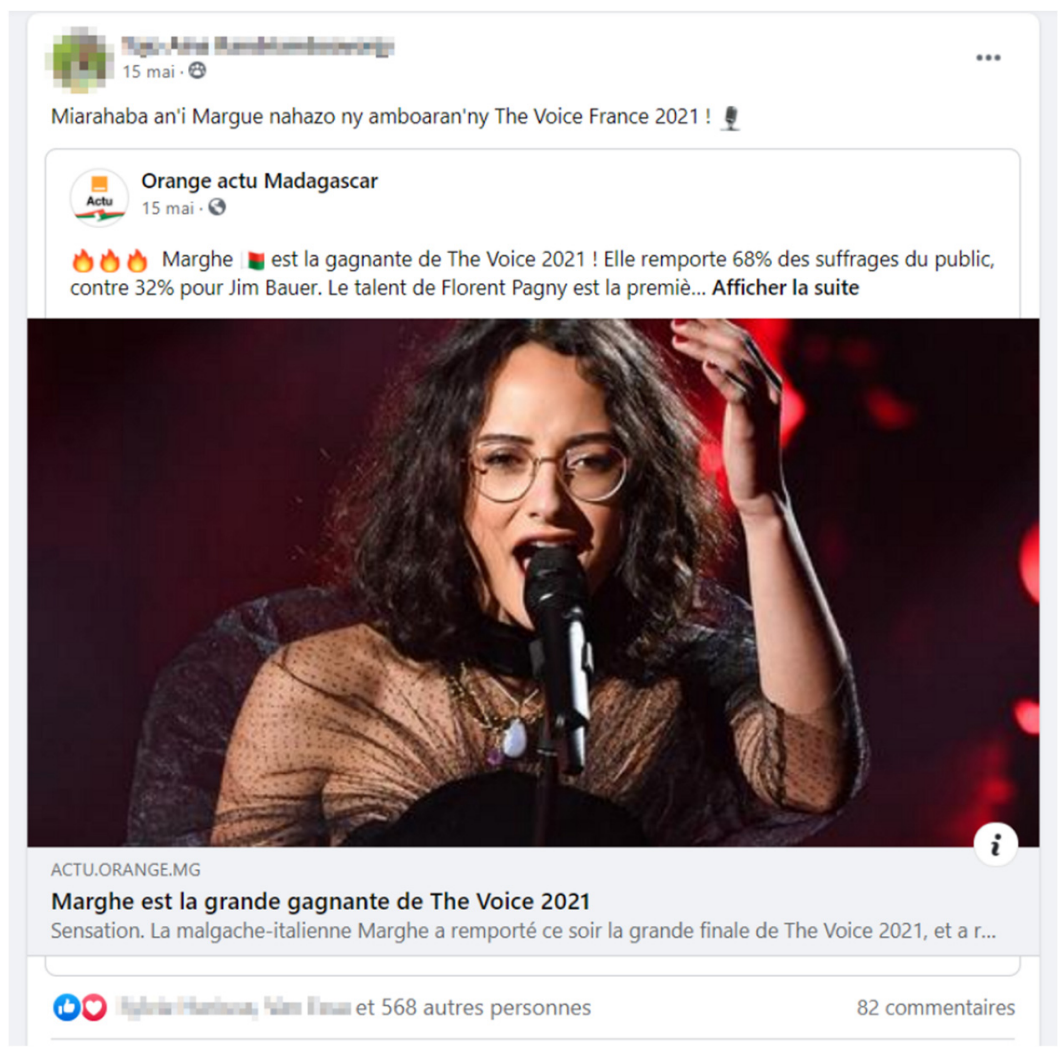

Figure 3. Capture of a post on 'Marghe' in the 'Za Koa Hanorina' Group. 
In the same line, collective support among Malagasy people in France for Malagasy talents from all sectors and levels is widespread among the groups and pages. This is the case for posts about Aina Ramadison, Ambassador of Madagascar within the International Organisation of Gastronomy and competitor in the "Best Chefs Africa" awards, and the same was true for Michael Arivony, a baritone participant in the "BBC Cardiff Singer of the World" awards and Nantenaina Mazava, a Madagascar-rooted basketball player playing with a basketball team in Florida (USA).

This flag-motivated solidarity shared by the members of the groups contrasts with a manifest and collective dissatisfaction vis-à-vis Malagasy institutions. The Malagasy embassy in Paris, as the supreme representation of Malagasy institutions in the metropolitan French territory, was regularly questioned by members of Malagasy groups in France and aroused intense interactions. Within the groups observed, this embassy was mostly negatively judged for the quality of its consular services (its institutional activities) as well as for its relationship with the Malagasy in France (its humanitarian activities). These judgments were made through posts describing the experiences of some members of the groups and pages as users of these institutions. In March 2020, for example, a woman posted a request in the GSF group: "Mba saika hangataka feedback ho an'ny olona nanao passport taty amin'ny Ambassade, mety firy volana vo vita kay azafady?" ("I would like feedback from someone who has applied for a passport renewal with the Madagascan Embassy in Paris, how many months does it take them, please?"). The responses were divided between those who proposed the best procedures based on their personal experiences, those who relativised the effectiveness of the embassy, and those who ironically laughed at it: "Omeo anay anio ny "deadline fanaovana passport" sahaza ho anay." ("Give us this day the duration of passport renewal") or even "Ataovy mafimafy ny fivavahana." ("Strengthen your prayers"). Another appeal was also particularly interesting. In line with the group's rule of avoiding any references to politics, a post in the group in September 2020 made by one of the managers of the GSF group asked the embassy about its duties of solidarity towards its citizens and resulted in numerous reactions (203 reactions and 167 comments in one day), with some very negative comments directed at the embassy. This post shows the magnitude of the distance between the Malagasy people in France and Malagasy institutions, such as the Malagasy embassy in Paris, as well as the weight of peer-to-peer and non-institutional solidarity among the Malagasy in France.

To conclude this section, the thematic analysis of the interactions of Malagasy migrants within their groups and Facebook pages describes the types of adversities they face and reveals the nature of the solidarity they put in place to deal with such adversities. On the one hand, there is sustained solidarity in responding to frequent and continuous needs, such as a common search for a solution to administrative issues, despite their recurrence within the groups and pages. On the other hand, solidarity in responding to sporadic necessity with a greater emotional component, such as the case of Bebe Antsika or Marghe in The Voice contest, elicits a lively interaction from the members of the group(s). In other words, the emotional component of the adversities seems to have a greater impact on the members of the groups and pages than frequency and 'practicality'. Additionally, we have discovered that there are several efficient patterns in which solidarity chains work. Some solidarity chains are born within the groups and/or pages and thereafter end offline (such as in the case of Bebe Antsika). There is also the opposite case: some chains of solidarity take shape outside social networks and are brought into them (such as the case where support was offered to a student economically affected by the COVID-19 pandemic).

\subsection{Self-Structured Solidarity Organisations on Facebook and Offline}

While the results of the Netnography allow us to discover the ongoing mechanisms of solidarity put in place by Malagasy migrants in France on Facebook, the results of the online survey presented in this section complement those of the Netnography and are intended to explore the personal intentions of Malagasy migrants in using Facebook as a tool and a place for solidarity. 
The results of the online survey show that a large majority of the Malagasy migrants who participated in the questionnaire $(92 \%, \mathrm{n}=314)$ declare affiliation to at least one Facebook group and/or page created and/or run by Malagasy migrants. This complements our finding in the Netnography that Facebook groups and pages of Malagasy migrants are very active and popular.

Among the Malagasy migrants in France who declare that they are a member of at least one Facebook group and/or page, a majority of them $(66 \%, n=207)$ declare that they are affiliated with at least an offline organisation-association or NGO_run by Malagasy migrants and, at the same time, a majority of them $(61 \%, n=191)$ declare that they are not affiliated with the Malagasy embassy in France (see AF 1.2 and AF 2.1 of Figure 4). In other words, while the Malagasy migrants are very active in associations and on Facebook, they seem to be reluctant when it comes to the affiliation with Malagasy institutions.

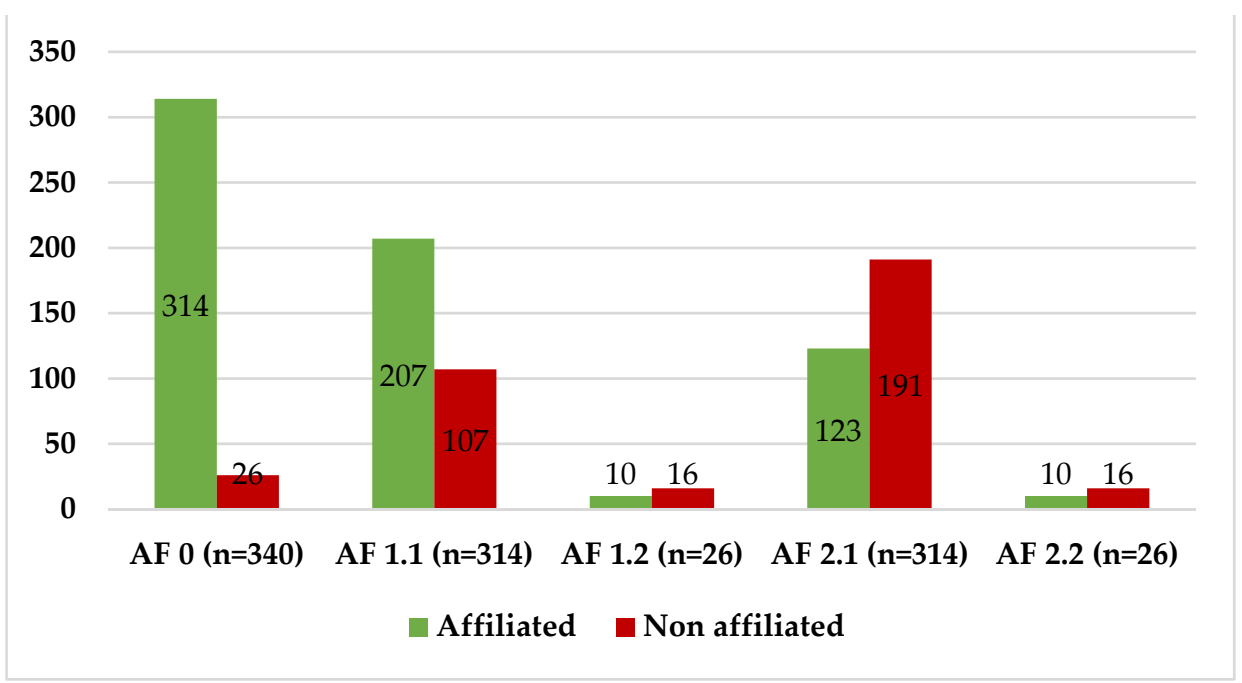

Figure 4. Distribution of the affiliation of informants with Facebook groups, with the Malagasy Embassy in France, and with offline organisation(s) of Malagasy migrants. AF 0: Affiliation with Facebook groups ( $\mathrm{n}=340)$; AF 1.1: Facebook-affiliated informants also affiliated with offline Malagasy group(s) ( $\mathrm{n}=314)$; AF 1.2: Facebook-affiliated informants who are not affiliated with offline Malagasy group(s) ( $\mathrm{n}=26)$ AF 2.1: Facebook-affiliated informants who are affiliated with the Malagasy Embassy $(\mathrm{n}=314)$; AF 2.2: Facebook-affiliated informants who are not affiliated with the Malagasy Embassy $(n=26)$.

Regarding their day-to-day use of Facebook, the majority of the Malagasy community in France who are affiliated with any group or page of Malagasy migrants on Facebook $(57 \%, \mathrm{n}=180)$ state that they frequent them at least once a day. Almost one-third $(30 \%$, $\mathrm{n}=93$ ) declare that they consult the group(s) and/or page(s) they are affiliated with more than once a week. The rest $(13 \%, \mathrm{n}=41)$ declare that they check the group(s) and/or page(s) they are affiliated with at least once a week or monthly.

When it comes to action on the group(s) and/or page(s) they are affiliated with, most of the Malagasy in France $(69 \%, n=218)$ declare that they use them mainly to observe the posts and comments made by other members of the groups and/or pages. A total of $53 \%$ $(n=168)$ of those who declare that they are members of at least one group and/or page indicate that they are inclined to react to ongoing interactions or publications. A relative minority of $27 \%(n=84)$ say that they actively use these groups and pages to create and/or share a post to generate discussion. What makes this finding curious is that while the majority of the Malagasy migrants declare being affiliated with at least one group or page of the Malagasy migrants, only a few report using them in an active way.

Most of the Malagasy migrants in France affiliated with at least one of these groups or pages declare using them mostly to learn about the news from their country of origin and/or their host country $(69 \%, n=218)$. Approximately one-third of Malagasy migrants 
$(32 \%, \mathrm{n}=101)$ report using them to discuss the social, political, and/or economic situation of their country of origin and/or their host country, among other motives. Another third of them $(31 \%, \mathrm{n}=98)$ declare using them mainly to maintain emotional bonds with their country of origin, among other motives. A total of $21 \%(n=66)$ declare using the groups and/or pages for ethnic commercial motives (to sell and/or buy products from Madagascar in France) or to organise or search for Malagasy cultural events in their host country. It is therefore clear that these Malagasy migrants use these Facebook groups and pages mainly as newsrooms.

\section{Discussion and Conclusions}

This paper presents specific and yet essential aspects of the online communities and communitarian solidarity actions of Malagasy migrants in France through an analysis of their Facebook groups and pages.

The results of the Netnography show that Malagasy migrants in France rely on very active and popular networks of self-organised and non-institutional groups and pages on Facebook. These groups and pages are driven by different purposes but serve as a gathering space for heterogeneous members that unite individuals that share the same culture, language, and country without having had any previous contact or relationship offline. Additionally, these Facebook groups and pages were found to be hubs for active and ongoing 'peer-to-peer' chains of solidarity. On the one hand, there is sustained solidarity in responding to frequent and continuous necessity, such as a common search for a solution to specific administrative issues despite their recurrence within the groups and pages. On the other hand, solidarity in responding to sporadic necessity with a greater emotional component, such as the case of Bebe Antsika or Marghe in The Voice contest, elicits a lively interaction from the members of the group(s). In other words, the emotional component of the adversities seems to have a greater impact on the members of the groups and pages than frequency and 'practicality'.

Some solidarity chains are born within the groups and/or pages and thereafter end offline (for example, the case of Bebe Antsika). The opposite-chains of solidarity that take shape outside social networks and are brought into them-was also found in the case where support was offered to a student economically affected by the COVID-19 pandemic.

The most striking finding here is that there are multiple factors to account for in the 'peer-to-peer' nature of these interactions. First, the solidarity chains are above all non-institutional actions that take place between ordinary citizens. They exist between peers who share common cultural factors and a common country of origin. Additionally, these solidarity chains take place between people who share the social experience of being migrants. The experience of the Malagasy migrants in France is, however, quite different from the solidarity chains of other migrant communities from low-income countries in high-income countries, such as the Bulgarians in the United Kingdom or the dynamics of some African diasporas in the US (Mesbah and Cooper 2019). In fact, if we compare the Facebook groups and pages of the Malagasy migrants in France with those of Bulgarians in the UK, we notice (i) that the Malagasy in France have no specific group or page dedicated to professional exchanges, and (ii) that posts related to this topic in general groups are less frequent than within the Facebook groups and pages of Bulgarians in the UK, as reported by Nancheva (2021). Overall, we believe that this is intimately related to the high level of integration of the Malagasy in France and to their high educational qualifications, as described by Razafindrakoto et al. (2017). This results in the Malagasy needing less support from their peers in the areas of work and business. Another possible explanation has to do with the role of offline associations, which seem to be "safer" spaces for face-to-face exchanges on such vital matters. These associations contrast with online public platforms such as Facebook, where the phenomenon of "social downgrading" would be more difficult to bear if publicly displayed.

This paper, like those listed above, sustains the concept of 'imagined communities' that Tsagarousianou (2004) mentions. Do the Malagasy migrants form a real 'community' 
within their Facebook groups and pages? If we understand this concept to refer to the existence of solidarity and mutual aid among members of a group gathered around shared factors, such as country of origin and the cultural factors detailed in this paper, we can easily answer the question affirmatively. If we understand the concept in its 'organisational' and structural sense, we could answer affirmatively as well. However, if the concept of 'community' were to be understood in the sense of legal and moral duties towards members of the same community (assistance) or towards the community itself (regular financial contributions or fees and membership card), the answer is no. This same debate can also be extended to other contexts of online gathering and is not limited to only migrant groups, as Cervi's (2019) study of online travel recommendation groups attests.

This paper contributes to the understanding of the dynamics of the Malagasy community in France in their groups and pages on a general platform such as Facebook. Future research on other more specific platforms such as LinkedIn could reveal additional factors of professional mutual support among the Malagasy community in France in terms of work and business and other aspects of this community.

Author Contributions: Conceptualization, F.M.A. and C.R-C.; methodology, F.M.A. and C.R.-C.; validation, C.R.-C.; formal analysis, F.M.A.; investigation, F.M.A.; data curation, F.M.A.; writing—original draft preparation, F.M.A.; writing-review and editing, C.R.-C.; visualization, C.R.-C.; supervision, C.R.-C.; project administration, F.M.A. All authors have read and agreed to the published version of the manuscript.

Funding: This research received no external funding.

Institutional Review Board Statement: The study was conducted according to the guidelines of the Declaration of Helsinki and following the personal data protections. The name(s), surname(s), phone number(s) or email of the informant were not asked.

Informed Consent Statement: Informed consent was obtained from all subjects involved in the survey.

Data Availability Statement: According to the survey protocol accepted by the informants of the survey, the entire data will be only available to the authors of the study.

Conflicts of Interest: The authors declare no conflict of interest.

\section{References}

Aboussi, Mourad. 2020. The Emigrant Political Participation in Morocco and Tunisia: Diasporic Civil Society and the Transnationalization of Citizenship in the Arab Spring Context. Journal of North African Studies 25: 228-50. [CrossRef]

Ajder, Teodor. 2020. Romanian Diasporic Facebook Groups as Public Spheres. Open Cultural Studies 2: 723-34. [CrossRef]

Amin, Kritika Premnath, Mark D. Griffiths, and Deena Dimple Dsouza. 2020. Online Gaming During the COVID-19 Pandemic in India: Strategies for Work-Life Balance. International Journal of Mental Health and Addiction. [CrossRef]

Anderson, Benedict. 1983. The Imagined Communities. Reflections on the Origin and Spread of Nationalism. Edited by Benedict Anderson. London: Verso.

Andrianimanana, Fortunat, and Carles Roca-Cuberes. 2019. Online weak ties, a sign of a diaspora in-the-making? The case of the Malagasy abroad. Sociologija 61: 631-43. [CrossRef]

Bowler, Gary M., Jr. 2010. Netnography: A Method Specifically Designed to Study Cultures and Communities Online. Qualitative Report 15: 1270-75. [CrossRef]

Cervi, Laura. 2019. Travellers' Virtual Communities: A Success Story. Universitas-Revista De Ciencias Sociales Y Humanas 30: 97-125. [CrossRef]

Christiansen, Connie Carøe. 2004. News Media Consumption among Immigrants in Europe: The Relevance of Diaspora. Ethnicities 4: 185-207. [CrossRef]

Christensen, Miyase. 2012. Online Mediations in Transnational Spaces: Cosmopolitan (Re)Formations of Belonging and Identity in the Turkish Diaspora. Ethnic and Racial Studies 35: 888-905. [CrossRef]

Claverie, Éric. 2011. Trente-cinq ans de Rencontres nationales sportives. Unité et identité malgaches. Hommes E Migrations 1289: 70-79. [CrossRef]

Claverie, Éric, and Évelyne Combeau-Mari. 2011. La rencontre nationale sportive malgache et sa revue Trait d'union. Migrations Société 137: 111-28. [CrossRef]

Crenn, Chantal. 1994. Malgaches de Bordeaux, entre intégration et recherches identitaires. Hommes et Migrations 1180: 10-16. [CrossRef]

DataReportal. 2020. Digital 2021: Global Overview Report-DataReportal-Global Digital Insights. Available online: https:/ / datareportal.com/reports / digital-2021-global-overview-report?utm_source=Reports\&utm_medium=PDF\&utm_ campaign=Digital_2021\&utm_content=Dual_Report_Promo_Slide (accessed on 5 October 2021). 
Diminescu, Dana. 2008. The Connected Migrant: An Epistemological Manifesto. Social Science Information 47: 565-79. [CrossRef]

Diminescu, Dana. 2012. Introduction: Digital Methods for the Exploration, Analysis and Mapping of e-Diasporas. Social Science Information 51: 451-58. [CrossRef]

Elling, Agnes, Ivo Van Hilvoorde, and Remko Van Den Dool. 2014. Creating or Awakening National Pride through Sporting Success: A Longitudinal Study on Macro Effects in the Netherlands. International Review for the Sociology of Sport 49: 129-51. [CrossRef]

Ellison, Nick. 2013. Citizenship, Space and Time: Engagement, Identity and Belonging in a Connected World. Thesis Eleven 118: 48-63. [CrossRef]

Georgiou, Myria. 2019. Diaspora and the Plurality of Its Cosmopolitan Imaginaries. In The Handbook of Diasporas, Media, and Culture. Edited by Roza Tsagarousianou and Jessica Retis. Hoboken: Wiley-Blackwell, pp. 63-76. [CrossRef]

King, Daniel L., Paul H. Delfabbro, Joel Billieux, and Marc N. Potenza. 2020. Problematic Online Gaming and the COVID-19 Pandemic. Journal of Behavioral Addictions 9: 184-86. [CrossRef]

Kotlok, Nathalie. 2016. Étude du profil de la diaspora malagasy en France. Geneva: International Organisation for Migration.

Kozinets, Robert V. 2002. Field behind the Screen: Using Netnography for Marketing Research in Online Communities. Journal of Marketing Research 39: 61-72. [CrossRef]

Kozinets, Robert V. 2010. Netnography: Doing Ethnographic Research Online. Southend Oaks: SAGE Publications Ltd.

Kriz, Willy C. 2020. Gaming in the Time of COVID-19. Simulation and Gaming 51: 403-10. [CrossRef]

Kumar, Priya. 2012. Transnational Tamil Networks: Mapping Engagement Opportunities on the Web. Social Science Information 51: 578-92. [CrossRef]

Lebow, Jay L. 2020. Family in the Age of COVID-19. Family Process 59: 309-12. [CrossRef]

Marino, Sara. 2015. Making Space, Making Place: Digital Togetherness and the Redefinition of Migrant Identities Online. Social Media + Society 1: 1-9. [CrossRef]

Mesbah, Hesham, and Lauren Cooper. 2019. Facebook Communities of African Diasporas and Their U.S. Embassies: A Content Analysis Study. In Multidisciplinary Issues Surrounding African Diasporas. Edited by Nancy Erbe. Dominguez-Hills: IGI Global, pp. 131-51.

Nancheva, Nevena. 2021. Cleaners and Labourers on Facebook? Bulgarians in the UK between Free Movers and a Digital Diaspora. Journal of Ethnic and Migration Studies 1-19. [CrossRef]

Parish, Helen. 2020. The Absence of Presence and the Presence of Absence: Social Distancing, Sacraments, and the Virtual Religious Community during the Covid-19 Pandemic. Religions 11: 1-13. [CrossRef]

Rabeherifara, Jean Claude. 2009. Malagasin'Andafy-France. Identités, réseaux et pratiques. In Madagascar revisitée. En voyage avec Françoise Raison-Jourde. Edited by Didier Nativel and Françoise Rajaonah. Paris: Karthala, pp. 153-77.

Rakotoary, Sarah. 2019. Usages de Facebook dans l'évènementialisation de la construction d'une communauté transnationale. Uses of Facebook to Promote the Construction of a Transnational Community. Communiquer. Revue de Communication Sociale et Publique 25: 23-37. [CrossRef]

Razafindrakoto, Mireille, Nicolas Razindratsima, Nirintsoa Razakamanana, and François Roubaud. 2017. La Diaspora Malagasy En France et Dans Le Monde: Une Communauté Invisible? Paris: DIAL. Available online: https: / /www.documentation.ird.fr/hor/fdi: 010072515 (accessed on 19 July 2021).

Tsagarousianou, Roza. 2004. Rethinking the Concept of Diaspora: Mobility, Connectivity, and Communication in a Globalised World. Westminster Papers in Communication and Culture 1: 52-65. [CrossRef]

Twigt, Mirjam A. 2018. The Mediation of Hope: Digital Technologies and Affective Affordances Within Iraqi Refugee Households in Jordan. Social Media and Society 4. [CrossRef]

Wiederhold, Brenda K. 2020. Social Media Use during Social Distancing. Cyberpsychology, Behavior, and Social Networking 23: 275-76. [CrossRef]

Wilson, Robert E., Samuel D. Gosling, and Lindsay T. Graham. 2012. A Review of Facebook Research in the Social Sciences. Perspectives on Psychological Science 7: 203-20. [CrossRef] 